\title{
NMR Study of Choline Methyl Group of Phospholipids
}

\author{
By Zhe Zhou,*) Yukihisa OKumura, ${ }^{* *)}$ and Junzo Sunamoto*),**) \\ (Communicated by Seizo OKamura, M. J. A., Feb. 13, 1996)
}

\begin{abstract}
Dimyristoylphosphatidylcholine (DMPC) and 1,2-dimyristoylamido-1,2-deoxyphosphatidylcholine $\left(\mathrm{D}_{14} \mathrm{DPC}\right)$ were studied with ${ }^{1} \mathrm{H}$ - and ${ }^{31} \mathrm{P}$ - NMR. By using the nuclear Overhauser enhancement difference spectra (NOEDF) and the nuclear Overhauser effect spectroscopy (NOESY) in ${ }^{1} \mathrm{H}$ NMR, we found that the ${ }^{1} \mathrm{H}$ NMR chemical shift of $\mathrm{N}^{+}\left(\mathrm{CH}_{3}\right)_{3}$ of DMPC liposome is different from that of the $\mathrm{D}_{14} \mathrm{DPC}$ liposome. It was also found that in $\mathrm{D}_{14} \mathrm{DPC} / \mathrm{DMPC}$ mixed liposome $\mathrm{D}_{14} \mathrm{DPC}$ might prefer to locate in outer leaflet of the lipid bilayer similarly to the case of sphingomyelin (SPH). ${ }^{1} \mathrm{H}$-Detected ${ }^{13} \mathrm{C}$ NMR has been successfully used to measure the ${ }^{13} \mathrm{C}$ spin-lattice relaxation time $\left(T_{1}\right)$ of $\mathrm{N}^{+}\left(\mathrm{CH}_{3}\right)_{3}$ of DMPC liposome. The sensitivity with this method was higher by 16 times compared with that of ordinary inversion recovery (IR) method.
\end{abstract}

Key words : Phosphatidylcholine liposome; artificial boundary lipid; NMR; ${ }^{1} \mathrm{H}$-detected ${ }^{13} \mathrm{C}$ NMR; spin-lattice relaxation time.

Introduction. We have already synthesized a lipid, $\mathrm{D}_{14} \mathrm{DPC}$, which carries two amide bonds instead of ester bonds of regular lecithins. ${ }^{1) 2)} \mathrm{D}_{14} \mathrm{DPC}$ was capable of acting as a boundary lipid enabling a significant increase in the glycophorin reconstitution in the liposomal bilayers. ${ }^{1,2)}$ Therefore, by using this artificial boundary lipid, we could significantly improve efficiency of membrane protein transfer from erythrocyte, ${ }^{3)}$ B16 melanoma cells, ${ }^{4)}$ and human platelets $^{5)}$ to the artificial boundary lipid-containing liposome. In addition, Nakamura et al. demonstrated that the protein transfer using $\mathrm{D}_{14} \mathrm{DPC}$-containing liposome is applicable even to an animal tissue such as epithelium of bullfrog tongue. ${ }^{6)}$ Shibata et al. found very effective tumor rejection of semi-syngeneic mice when sensitized by the $\mathrm{D}_{14} \mathrm{DPC}$-containing egg PC liposome. Also in this case, a tumor surface antigen protein was reconstituted into the liposome by the direct protein transfer method from BALBRVD leukemia cell. ${ }^{7), 8)}$

To understand actual behavior and functions of $\mathrm{D}_{14} \mathrm{DPC}$ in a liposomal membrane, we further studied

\footnotetext{
*) Supermolecules Project, Research Development Corporation of Japan, Keihanna Plaza, 1-7 Seika-cho, Soraku-gun, Kyoto 619-02, Japan.

**) Department of Synthetic Chemistry \& Biological Chemistry, Graduate School of Engineering, Kyoto University, Sakyoku, Yoshida Hommachi, Kyoto 606-01, Japan.
}

its conformation, location and dynamics by using ${ }^{1} \mathrm{H}$-, ${ }^{2} \mathrm{H}-,{ }^{13} \mathrm{C}$-, and ${ }^{31} \mathrm{P}-\mathrm{NMR}$ techniques. In this work, in addition, we applied the ${ }^{1} \mathrm{H}$-detected ${ }^{13} \mathrm{C}$ NMR technique, which was first developed by Palmer et al., ${ }^{9), 10)}$ for liposomal system to obtain ${ }^{13} \mathrm{C}-T_{1}$ of the choline methyl group of phospholipids in the liposome. We certified that this method can significantly improve the measurement sensitivity compared with the case of ordinary IR (inversion recovery) method.

Experimental. Materials. DMPC (Sigma Chemical Co., St. Louis, U.S.A.), $\mathrm{D}_{14} \mathrm{DPC}$ (Dojindo Laboratories, Kumamoto, Japan) and all other reagents were commercially available.

Preparation of liposomes. Lipids were dissolved in $\mathrm{CHCl}_{3} / \mathrm{CH}_{3} \mathrm{OH}$ (2:1 by volume), and the solvent was removed under reduced pressure. The thin film formed on the wall of a test tube was completely dried overnight under vacuum. The lipid thin film was suspended in deuterium-substituted phosphate buffered saline (PBS) $(5 \mathrm{mM}$ sodium phosphate and 150 $\mathrm{mM} \mathrm{NaCl}(\mathrm{pD}=7.5))$. The lipid suspension was passed through a series of Nucleopore polycarbonate membrane filters with subsequently decreased pore sizes (five times each in the sequence of $1,000,600,400$, and $200 \mathrm{~nm}$, and then ten times each with 100 and $50 \mathrm{~nm}$ ) set in an extruder (Lipex Biomembranes, Vancouver, Canada). ${ }^{5)}$

NMR experiments. NMR were acquired at 500.00 


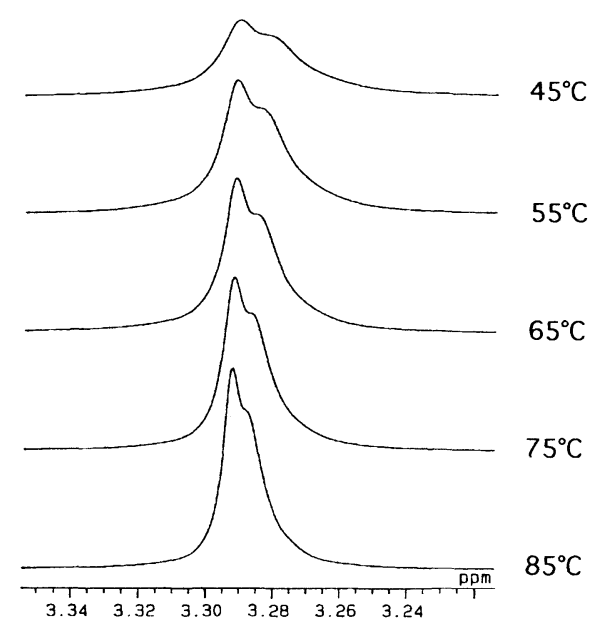

Fig. 1. ${ }^{1} \mathrm{H}$ NMR spectra of $50 \mathrm{~nm}$ DMPC liposome at different temperatures.

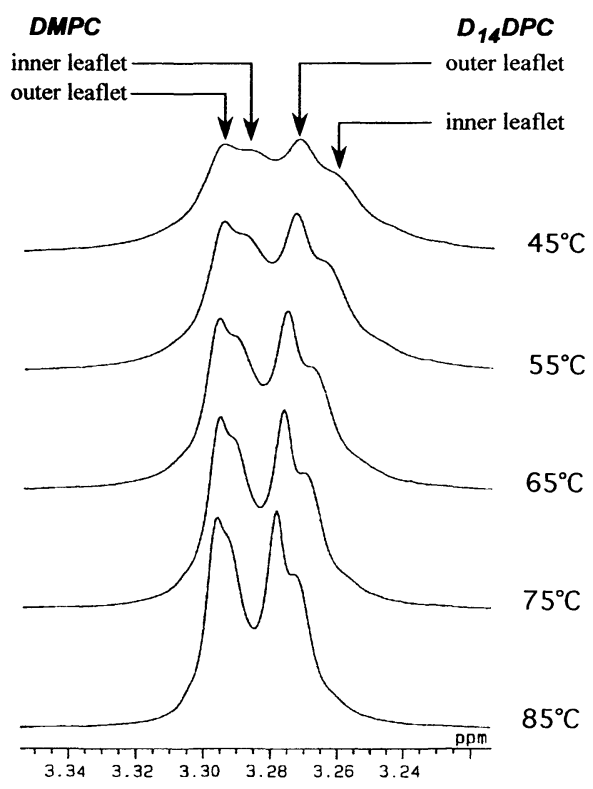

Fig. 2. ${ }^{1} \mathrm{H}$ NMR spectra of $50 \mathrm{~nm} \mathrm{D}_{14} \mathrm{DPC} / \mathrm{DMPC}$ (1:1, by $\mathrm{mol})$ liposome at different temperatures.

$\mathrm{MHz}$ for ${ }^{1} \mathrm{H}, 202.35 \mathrm{MHz}$ for ${ }^{31} \mathrm{P}$, and $125.65 \mathrm{MHz}$ for ${ }^{13} \mathrm{C}$ spectra on a JEOL $\alpha-500 \mathrm{NMR}$ spectrometer with a temperature control.

Results and discussion. With DMPC and $\mathrm{D}_{14} \mathrm{DPC} / \mathrm{DMPC}$ (1:1 by mol) liposomes, no dramatic difference was observed in the chemical shift for $\left(-\mathrm{CH}_{2}\right)_{\mathrm{n}}$ and $\omega-\mathrm{CH}_{3}$ groups of acyl chains except the intensity. However, the situation was quite different for the choline methyl group. Fig. 1 shows the ${ }^{1} \mathrm{H}$ NMR signals of pure DMPC liposome measured over a range from 3.215 to $3.355 \mathrm{ppm}$ at various tempera- tures. Fig. 2 shows the ${ }^{1} \mathrm{H}$ NMR spectra of $\mathrm{D}_{14} \mathrm{DPC} /$ DMPC (1:1 by mol) liposome.

In unilamellar liposomal system, the ${ }^{1} \mathrm{H}$ NMR chemical shift of the choline methyl group of $\mathrm{D}_{14} \mathrm{DPC}$ is different from that of DMPC. Of four broad peaks, two peaks of the lower field are assigned to the choline methyl group of DMPC, while another two peaks of the higher field are that of $\mathrm{D}_{14} \mathrm{DPC}$. They were of course directly assigned by comparing with the chemical shift of corresponding single lipid liposomes. This is really a new finding in this work, because this is contrary to what was previously reported. ${ }^{11)}$ People has believed that the choline methyl groups of the phosphatidylcholine liposomes are in the same chemical environment and subsequently show the same or almost same chemical shift even in a mixed phospholipid liposome. Therefore, the difference in the chemical shift of the choline methyl groups between $\mathrm{D}_{14} \mathrm{DPC}$ and DMPC (Fig. 2) should come from the different chemical environment between the two in the mixed liposomal membrane. In order to understand this unexpected result, we had to study using (1) a NMR spectrometer with higher magnetic field to distinguish small chemical shift difference, (2) at higher temperature to increase resolution, and (3) with a liposome having a suitable size.

It is well known that the choline methyl group of phospholipids in liposome shows NOE with adjacent phospholipids. ${ }^{12)}$ Therefore, if they are irradiated with appropriate radio-frequency, we can observe the NOE phenomena from the choline methylene protons $\left(-\mathrm{CH}_{2} \mathrm{CH}_{2}-\mathrm{N}^{+}-\right)$. Fig. 3a shows a regular ${ }^{1} \mathrm{H}$ NMR spectrum of the $\mathrm{D}_{14} \mathrm{DPC} / \mathrm{DMPC}$ liposome over a range of $3.85-3.23 \mathrm{ppm}$ at $60^{\circ} \mathrm{C}$. A broad peak at $3.717 \mathrm{ppm}$ (the part of lower magnetic field in Fig. 3a) is the overlapped signal of whole the choline methylene protons, while peaks of the right hand side are from the choline methyl protons of the lipids as described above (Figs. 1 and 2). Figs. $3 \mathrm{~b}$ and $\mathrm{c}$ are NOEDF of the mixed lipid system. We observed NOE on the choline methylene proton signal when we irradiated the choline methyl proton signal of DMPC in the outer leaflet at $3.295 \mathrm{ppm}$ (vide infra). Similarly, when we irradiated the signal at $3.274 \mathrm{ppm}$, the same NOE phenomena was again observed on the choline methylene proton signal (the part of lower magnetic field of Fig. 3c). We further confirmed this assignment by using NOESY experiment. Fig. 4 shows the NOESY spectrum of the $\mathrm{D}_{14} \mathrm{DPC} / \mathrm{DMPC}$ liposome at $60^{\circ} \mathrm{C}$. It is easily understood that there are two cross 


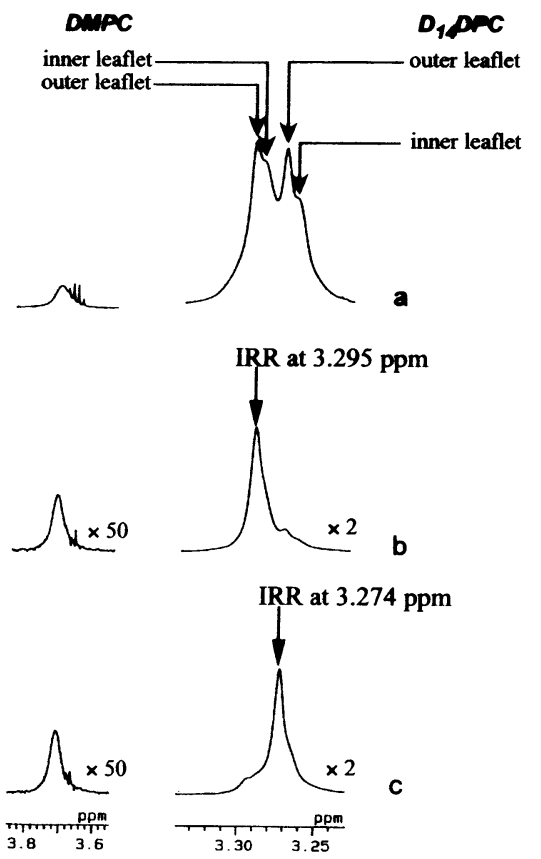

Fig. 3. ${ }^{1} \mathrm{H}$ NMR spectra of $50 \mathrm{~nm} \mathrm{D}_{14} \mathrm{DPC} / \mathrm{DMPC}(1: 1$, by mol) liposome at $60^{\circ} \mathrm{C}$. (a) Regular ${ }^{1} \mathrm{H}$ NMR spectrum; (b) NOEDF spectrum irradiated at $3.295 \mathrm{ppm}$; (c) NOEDF spectrum irradiated at $3.274 \mathrm{ppm}$.

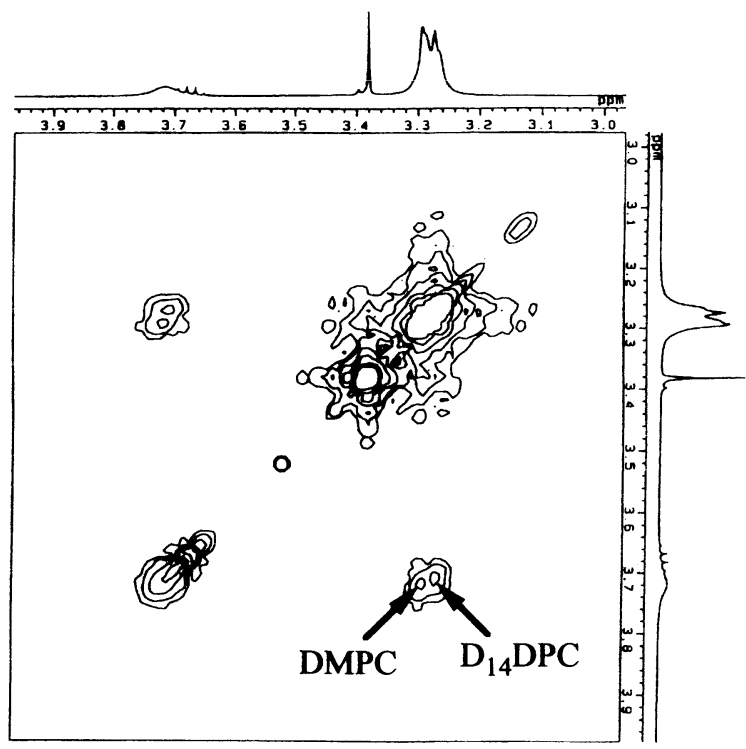

Fig. 4. NOESY spectrum of $\mathrm{D}_{14} \mathrm{DPC} / \mathrm{DMPC}(1: 1$, by mol) liposome at $60^{\circ} \mathrm{C}$.

peaks between the choline methylene proton signal and the signals that are expected to be the choline methyl protons.

Another interesting finding in this work is the asymmetric location of the two lipids, DMPC and

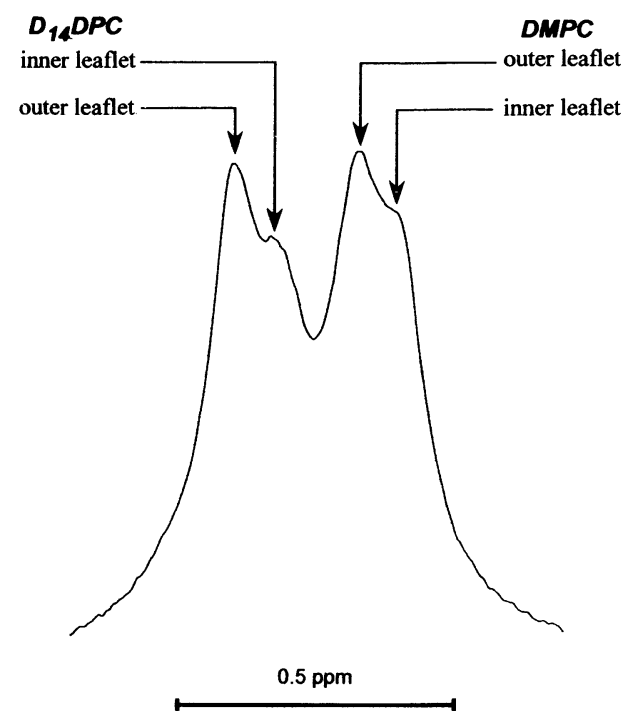

Fig. 5. ${ }^{31} \mathrm{P}$ NMR spectrum of $\mathrm{D}_{14} \mathrm{DPC} / \mathrm{DMPC}$ (1:1, by mol) liposome at $75^{\circ} \mathrm{C}$.

$\mathrm{D}_{14} \mathrm{DPC}$, in the lipid bilayer. The choline methyl protons of the lipid in the inner leaflet resonance at higher magnetic field, while those in the outer leaflet resonance at lower magnetic field. ${ }^{13)}$ As seen in the ${ }^{1} \mathrm{H}$ NMR of DMPC (Fig. 1), there exist two separated peaks; one of them appeared at the higher field corresponds to the lipid locating in the inner leaflet, and the other intense peak at the lower field comes from the lipid in the outer leaflet. The reason may be the following. The lipids in the inner leaflet are more densely packed than the lipids being in the outer leaflet, leading to a requirement of higher field strength for the resonance. When temperature becomes higher, the difference in the chemical shift between the inner and the outer leaflets becomes smaller. This can be understood as evidence that an increase in the mobility of the lipid headgroup causes a decrease in the effect of packing density. The results of NOEDF with the $\mathrm{D}_{14} \mathrm{DPC} / \mathrm{DMPC}$ liposome (Fig. 3) also supported that the signal at $3.274 \mathrm{ppm}$ is from the choline methyl group of $\mathrm{D}_{14} \mathrm{DPC}$ in the outer leaflet, while the peak at $3.265 \mathrm{ppm}$ is from the lipid in the inner leaflet. This was also true in the ${ }^{31} \mathrm{P}$ NMR for the $\mathrm{D}_{14} \mathrm{DPC} / \mathrm{DMPC}$ (1:1 by mol) liposome (Fig. 5 ). In the ${ }^{31} \mathrm{P}$ NMR, contrary to what was observed in the ${ }^{1} \mathrm{H}$ NMR, the phosphorous signal of $\mathrm{D}_{14} \mathrm{DPC}$ appeared at the lower magnetic field than that of DMPC. The assignment was also made by comparison of the chemical shifts in each single lipid system. In any event, judging from these results, it is clear that 


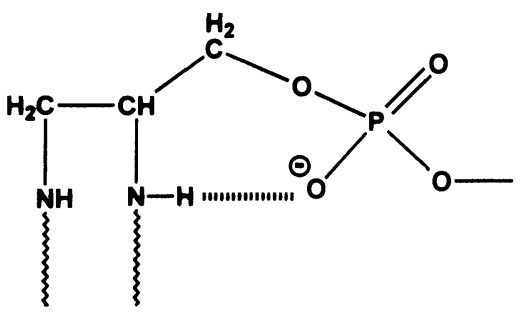

Fig. 6. Schematic drawing of intramolecular hydrogen bonding in the $\mathrm{D}_{14} \mathrm{DPC}$ head group.

$\mathrm{D}_{14} \mathrm{DPC}$ prefers to locate more in the outer leaflet compared with DMPC.

What is the reason that $\mathrm{D}_{14} \mathrm{DPC}$ prefers to be more in the outer leaflet than DMPC in the mixed lipid bilayer? This would be due to formation of an intramolecular hydrogen bonding in $\mathrm{D}_{14} \mathrm{DPC}$ (Fig. 6). ${ }^{14), 15)}$ Such the intramolecular hydrogen bonding was also proposed for SPH by Berden et al. ${ }^{11)}$ Through ${ }^{31} \mathrm{P}$ NMR studies of eggPC/SPH liposomal system, they found that SPH prefers to locate more in the outer leaflet of the bilayer upon the formation of intramolecular hydrogen bonding. Curvature of the outer leaflet of liposome is smaller than that of the inner leaflet. These may be reasons that $\mathrm{D}_{14} \mathrm{DPC}$ also has a preference to be in the outer leaflet of lipid bilayers similarly to SPH. To obtain the exact amount ratio of these lipids in the asymmetric location, either in the inner or in the outer leaflet, we are now in progress by mathematical and computational simulation on data of ${ }^{1} \mathrm{H}$ and ${ }^{31} \mathrm{P}$ NMR in various mixed lipid systems. ${ }^{16)}$

Membrane dynamics of the $\mathrm{D}_{14} \mathrm{DPC}$-containing liposomes is another important problem to us. For this purpose, ${ }^{13} \mathrm{C}-T_{1}$ measurement is promising because the relaxation parameters of ${ }^{13} \mathrm{C}$ are governed by dipolar interaction with protons directly attached. In general, the interpretation of the ${ }^{13} \mathrm{C}$ relaxation data does not require whole chemical structure of the molecule under consideration, unlike ${ }^{1} \mathrm{H}$ relaxation studies. Studies of the ${ }^{13} \mathrm{C}$ relaxation properties for biomolecules were originally based on direct observation of ${ }^{13} \mathrm{C}$ spectra with $1 \mathrm{D}$ NMR technique. However, most unfortunately, either ${ }^{13} \mathrm{C}$-labelled sample or substantial measuring time is required because of its low sensitivity of ${ }^{13} \mathrm{C}^{17)}$ Recently, Palmer ${ }^{9), 10)}$ and Nicholson ${ }^{18)}$ proposed the proton-detected carbon NMR method for measurement of ${ }^{13} \mathrm{C}-T_{1}$ for methyl group ( IS $_{3}$ system). This method provides a significant gain in the sensitivity and is useful to obtain the order parameter and the effective correlation time for
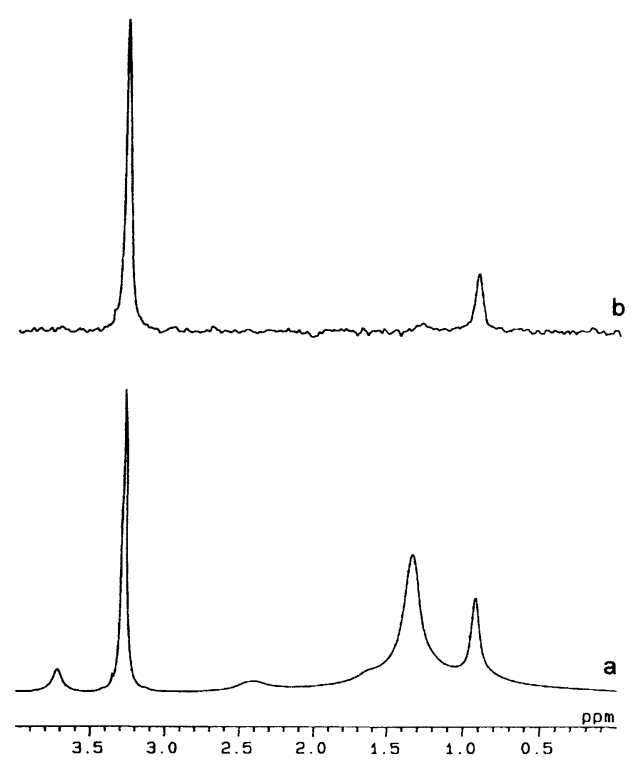

Fig. 7. NMR spectra of $50 \mathrm{~nm}$ DMPC liposome. (a) Regular ${ }^{1} \mathrm{H}$ NMR spectrum; (b) Spectrum measured with ${ }^{1} \mathrm{H}$-detected ${ }^{13} \mathrm{C}$ method. ${ }^{9)}$

methyl group of proteins. ${ }^{10), 18)}$ Hence, we tried to apply this proton-detected carbon NMR method $^{9)}$ to liposome system. To certify that this method is correct and applicable even to liposomal system, we of course carefully investigated in advance using a simple model, L-Met-methyl- ${ }^{13} \mathrm{C}\left({ }^{13} \mathrm{CH}_{3} \mathrm{SCH}_{2} \mathrm{CH}_{2} \mathrm{CH}\left(\mathrm{NH}_{2}\right) \mathrm{CO}_{2} \mathrm{H}\right)$, in $\mathrm{D}_{2} \mathrm{O}$. We found a very good agreement within error between the results: The $T_{1}$ was $6.0 \mathrm{sec}$ by the regular IR method, while it was $6.3 \mathrm{sec}$ by the present method. This certainly confirmed that the method proposed here is reliable and utilizable.

Fig. 7a shows the regular ${ }^{1} \mathrm{H}$ NMR spectrum of the DMPC liposome at $37^{\circ} \mathrm{C}$. The broad and intense peak at 3.28 ppm comes from $-\mathrm{N}^{+}\left(\mathrm{CH}_{3}\right)_{3}$, and a peak at $1.35 \mathrm{ppm}$ is mainly of the methylene protons of acyl chains. Another broad peak at $0.93 \mathrm{ppm}$ is due to $\omega$-CH$H_{3}$. Fig. $7 \mathrm{~b}$ shows the ${ }^{1} \mathrm{H}$ NMR spectrum of the DMPC liposome measured by the ${ }^{1} \mathrm{H}$-detected ${ }^{13} \mathrm{C}$ NMR pulse at $37.0^{\circ} \mathrm{C} .{ }^{9)}$ The peak at 1.35 ppm was completely suppressed, while the peaks at 3.28 and at $0.93 \mathrm{ppm}$ were left. By changing the mixing time of the pulse, ${ }^{9)}$ the ${ }^{13} \mathrm{C}-T_{1}$ for $\mathrm{N}^{+}\left(\mathrm{CH}_{3}\right)_{3}$ of DMPC was obtained to be $0.57 \pm 0.01 \mathrm{sec}$. The $T_{1}$ value obtained in this work was in good accordance with that previously reported by One and Prestegard using the regular IR method. ${ }^{19)}$ It is apparent that this new method enhances the sensitivity higher than the value of $\left(\gamma_{\mathrm{H}} / \gamma_{\mathrm{C}}\right)^{2},{ }^{9), 10)}$ where $\gamma_{\mathrm{H}}$ and $\gamma_{\mathrm{C}}$ are magnetogyric ratios 


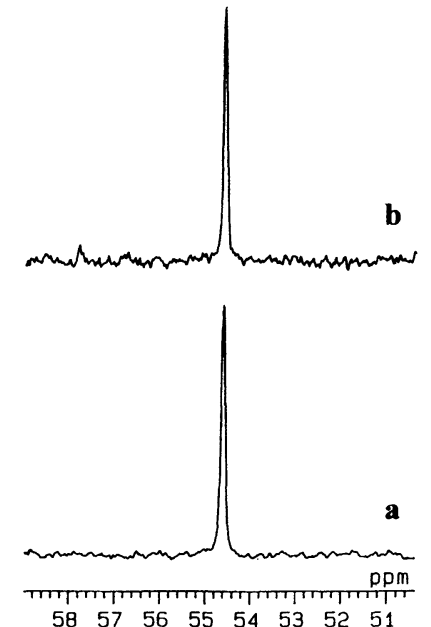

Fig. 8. ${ }^{13} \mathrm{C}$ NMR spectra for choline methyl groups. (a) $\mathrm{D}_{14} \mathrm{DPC} / \mathrm{DMPC}(1: 1$, by $\mathrm{mol})$ liposome at $60^{\circ} \mathrm{C}$. (b) DMPC/SPH (1:1, by mol) liposome at $75^{\circ} \mathrm{C}$.

of ${ }^{1} \mathrm{H}$ and ${ }^{13} \mathrm{C}$, respectively.

With $\mathrm{D}_{14} \mathrm{DPC} / \mathrm{DMPC}-$, DMPC/SPH-, $\mathrm{D}_{14} \mathrm{DPC} /$ DMPC/cholesterol- and $\mathrm{D}_{14} \mathrm{DPC} / \mathrm{DMPC} / \mathrm{DMPE}$-liposomes, it was impossible to obtain the independent information about dynamics of $\mathrm{N}^{+}\left(\mathrm{CH}_{3}\right)_{3}$ for each lipid when we employed the regular ${ }^{13} \mathrm{C}$ IR method, because all the ${ }^{13} \mathrm{C}$ signals of the choline methyl groups of lipids were overlapped in liposomal system. Fig. 8 shows ${ }^{13} \mathrm{C}$ NMR spectra for the choline methyl groups of the $\mathrm{D}_{14} \mathrm{DPC} / \mathrm{DMPC}(1: 1 \mathrm{by} \mathrm{mol})$ liposome at $60^{\circ} \mathrm{C}$ and DMPC/SPH (1:1 by mol) liposome at $75^{\circ} \mathrm{C}$. Unfortunately, all the choline methyl groups appeared at the same position. Although the resolution was not good enough with this method at present to obtain information about dynamics of the mixed liposome system at physiological temperature $\left(37^{\circ} \mathrm{C}\right)$, it seems possible to obtain the information if we used higher magnetic field.

Acknowledgments. We gratefully acknowledge Prof. Hisanobu Ogoshi for his kind help for the NMR measurement. We thank Mr. H. Utsumi of JEOL for his help to set up the new NMR technique.

\section{References}

1) Sunamoto, J., Nagai, K., Goto, M., and Lindman, B. (1990) Biochim. Biophys. Acta 1024, 220-226.

2) Sunamoto, J., Goto, M., Iwamoto, K., Kondo, H., and Sato, T. (1990) Biochim. Biophys. Acta 1024, 209-219.

3) Suzuki, K., Okumura, Y., Sato, T., and Sunamoto, J. (1995) Proc. Japan Acad. 71B, 93-97.

4) Sunamoto, J. Mori, Y., and Sato, T. (1992) Proc. Japan Acad. 68B, 69-74.

5) Okumura, Y. Ishitobi, M., Sobel, M., Akiyoshi, K., and Sunamoto, J. (1994) Biochim. Biophys. Acta 1194, 335-340.

6) Nakamura, M., Tsujii, K. Katsuragi, Y., Kurihara, K., and Sunamoto, J. (1994) Biochem. Biophys. Res. Commun. 201, 415-422.

7) Shibata, R., Noguchi, T., Sato, T., Akiyoshi, K., Sunamoto, J., Shiku, H., and Nakayama, E. (1991) Int. J. Cancer 48, 434-442.

8) Sunamoto, J., Noguchi, T., Sato, T., Akiyoshi, K., Shibata, R., and Nakayama, E. (1992) J. Controlled Release 20, 143-153.

9) Palmer, A. G., Wright, P. E., and Rance, M. (1991) Chemical Physics Letters 185, 41-46.

10) Palmer, A. G., Hochstrasser, R. A., Millar, D. P., Rance, M., and Wright, P. E. (1993) J. Am. Chem. Soc. 115, 6333-6345.

11) Berden, J. A., Barker, R. W., and Radda, G. K. (1975) Biochim. Biophys. Acta 375, 186-208.

12) Qiu, X., and Pidgeon, C. (1994) Biochemistry 33, 960-972.

13) Jendrasiak, G. L., Smith, R., and Ribeiro, A. A. (1993) Biochim. Biophys. Acta 1145, 25-32.

14) Kawai, T., Umemura, J., Takenaka, T., Gotou, M., and Sunamoto, J. (1988) Langmuir 4, 449-452.

15) Zhou, Z., Okumura, Y., and Sunamoto, J. (in preparation).

16) Ueda, T., Zhou, Z., and Sunamoto, J. unpublished results.

17) Brulet, P., and McConnell, H. M. (1976) Biochem. Biophys. Res. Commun. 68, 363-368.

18) Nicholson, L. K., Kay, L. E., Baldisseri, D. M., Arango, J., Young, P. E., Bax, A., and Torchia, D. A. (1992) Biochemistry 31, 5253-5263.

19) One, R. L., and Prestegard, J. H. (1982) Biochim. Biophys. Acta 692, 252-262. 